\title{
Dampak Pengembangan Pariwisata Dalam Rangka Meningkatkan Kesejahteraan Masyarakat Di Kawasan Objek Wisata Bukit Khayangan Kota Sungai Penuh
}

Putri Wahyuni ${ }^{1}$, Aldri Frinaldi ${ }^{2}$

Putri, Padang, Indonesia,

2Jurusan Ilmu Administrasi Publik, Fakultas Ilmu Sosial, Universitas Negeri Padang, Padang, Indonesia,

33Email : putriiwahyunii20@gmail.com;aldrifrinaldi@gmail.com;aldri@fis.unp.ac.id

\begin{abstract}
This study aims to describe how the development of tourism, including supporting and barrier factors of the government for development of Bukit Khayangan tourism object. And analyze the effect that come from the development of Bukit Khayangan tourism object to the economic of local community. This research uses a qualitative method with a descriptive approach. Data collection techniques in this research were conducted by interviews, observations, and documentation. The result showed that there was an increase in facilities after the development,although the cleanliness and safety still were not optimal. The development of Bukit Khayangan tourism object gives contribution to the increase of local community bussiness, one of them is to opening jobs for local community. But, the participation of local community need to be improved to moving forward improve overall the community welfare.
\end{abstract}

Keywords: Tourism Development, Economic Impact, Community Welfare.

\section{Pendahuluan}

Pengembangan pariwisata didasarkan pada amanat Undang-Undang No. 10 Tahun 2009 tentang Kepariwisataan yang menyatakan bahwa pemerintah bersama lembaga yang terkait dengan kepariwisataanmenyelenggarakan penelitian dan pengembangan kepariwisataan untuk mendukung pembangunan kepariwisataan (pasal 11 UU No. 10 Tahun 2009). Pengembangan pariwisata di Indonesia bertujuan untuk mengurangi kemiskinan, melestarikan alam, lingkungan dan sumber daya, mengembangkan budaya, memperbaiki citra bangsa, dan memperkuat hubungan dengan negara lain (Sutawa, 2012).

Potensi keindahan alam salah satunyaberada di Provinsi Jambi. Sebuah provinsi yang terletak tepatnya dibagian barat cekungan Pulau Sumatera. Kota Jambi memang dipenuhi banyak objek wisata, namun Sungai Penuh juga tak kalah dengan surganya yang masih terpendam. Sungai Penuh memiliki objek wisata yang pada 2017 lalu mampu memperoleh gelar sebagai The Most Popular Highland 2017 di Ajang Anugerah Pesona Indonesia, yaitu objek wisataBukit Khayangan yang 
merupakan sebuah bukit rangkaian dari bukit barisan yang mengelilingi daerah di Kerinci ini berlokasi di barisan Gunung Raya dan berada pada ketinggian 200 meter diatas permukaan laut. Penamaan Bukit Khayangan sendiri dikarenakan pemandangan yang disuguhkan ketika berada dispot center, berupa lautan awan yang menakjubkan.

Tabel 1.1. Jumlah Pengunjung Kawasan Objek Wisata Bukit Khayangan Tahun 2014-2018

\begin{tabular}{|ccccc|}
\hline Tahun & \multicolumn{2}{c}{$\begin{array}{c}\text { Wisatawan } \\
\text { Mancanegara }\end{array}$} & & Wisatawan Nusantara \\
\hline 2014 & 177 & $15,07 \%$ & 23.240 & $17,1 \%$ \\
\hline 2015 & 192 & $16,3 \%$ & 23.675 & $18,1 \%$ \\
\hline 2016 & 233 & $19,8 \%$ & 26.893 & $20,5 \%$ \\
\hline 2017 & 280 & $23,8 \%$ & 27.741 & $21,2 \%$ \\
\hline 2018 & 293 & $24,8 \%$ & 29.197 & $22,3 \%$ \\
\hline
\end{tabular}

Diolah Peneliti, 2019

Sumber: Dinas Kebudayaan dan Pariwisata Kota Sungai Penuh

Berdasarkan table diatas, terlihat bahwa jumlah kunjungan selalu meningkat setiap tahunnya. Eksistensi objek wisata Bukit Khayangan sudah mulai terlihat dengan banyaknya wisatawan nusantara yang berkunjung, termasuk wisatawan mancanegara yang juga ikut mengenal dan menikmati keindahan panorama Bukit Khayangan tersebut.

Pada dasarnya, pengembangan pariwisata bukan saja tanggung jawab pemerintah daerah, tetapi masyarakat juga harus ikut berperan aktif dengan tujuan agar terciptanya tempat pariwisata yang memiliki daya tarik untuk dikunjungi. Karena suatu objek wisata tentu akan berdampak bagi lingkungan sekitarnya terutama bagi masyarakat dikawasan objek wisata itu sendiri. Sehingga sangat dibutuhkan suatu bentuk kerjasama yang baik antara pengelola objek dengan masyarakat dikawasan objek wisata.

Belum optimalnya pengembangan objek wisata Bukit Khayangan dapat dilihat dari beberapa permasalahan, yaitu masih terdapat kekurangan yang menjadi kendala yang menunjukkan bahwa objek wisata Bukit Khayangan ini sepertinya memang dibutuhkan perhatian serius dari Pemerintah Daerah. Salah satu kendala yang ditemui yaitu dari segi infrastruktur, seperti jalan menuju lokasi wisata yang masih banyak ditemukan kerusakan berupa jalanan berlubangdan beberapa titik 
jalan yang rawan terjadi longsor sehingga secara tidak langsung akan membuat pengunjung yang dapat merasa kurang nyaman dengan infrastruktur yang ada.

Selain itu, penulis melihat bahwa banyaknya peluang usaha masih belum mampu dimanfaatkan dengan baik oleh masyarakat sekitar, sehingga kesejahteraan masyarakat dilingkungan wisata Bukit Khayangan Kota Sungai Penuh tersebut masih kurang. Hal ini disebabkan karena rendahnya minat masyarakat untuk membuka usaha di bidang pariwisata.

Berdasarkan latar belakang masalah diatas, maka penulis melakukan penelitian di kota Sungai Penuh mengenai Dampak Pengembangan Pariwisata Dalam Rangka Meningkatkan Kesejahteraan Masyarakat Di Kawasan Objek Wisata Bukit Khayangan Kota Sungai Penuh, Rumusan Masalah yang dikemukakan dalam penelitian ini adalah : 1) Bagaimana pengembangan objek wisata Bukit Khayangan Kota Sungai Penuh?, 2) Faktor-faktor apa saja yang mempengaruhi pengembangan pariwisata objek wisata Bukit Khayangan Kota Sungai Penuh?, 3) Bagaimana dampak pengembangan pariwisata dalam rangka meningkatkan kesejahteraan masyarakat di kawasan objek wisata Bukit Khayangan Kota Sungai Penuh?

\section{Metode Penelitian}

Dalam penelitian ini, peneliti menggunakan pendekatan kualitatif dengan metode deskriptif. Menurut Sugiyono (2014:301), purposive sampling adalah teknik penentuan sampel dengan pertimbangan tententu yang dipandang dapat memberikan data secara maksimal.Data yang digunakan dalam penelitian ini adalah data primer dan sekunder. Pengumpulan data dilakukan dengan cara wawancara, observasi dan studi Dokumentasi dengan uji keabsahan data trianggulasi sumber. Sedangkan untuk teknik analisis data dilakukan dengan cara redukasi data, penyediaan data dan penarikan kesimpulan.

\section{Hasil dan Pembahasan}

\section{Faktor-Faktor Yang Mempengaruhi Perkembangan Pariwisata}

Dalam penelitian ini, peneliti menggunakan teori faktor-faktor yang mempengaruhi perkembangan pariwisata yang dikembangkan oleh Gamal Suwantoro (dalam Dasar-Dasar Pariwisata, 2004:3). Teori tersebut digunakan berdasarkan kebutuhan penelitian. Adapun indikator dalam faktor-faktor yang mempengaruhi perkembangan pariwisata, adalah: Objek dan Daya Tarik Wisata, Prasarana Wisata, Sarana Wisata, Tata Laksana (infrastruktur), dan Masyarakat.

\section{Objek dan Daya Tarik Wisata}

Untuk melihat faktor yang menjadi pendukung dan penghambat dalam pengembangan pariwisata, dapat dilihat dari ungkapan pendapat Bapak Yan Kamal 
Syam, S.E, (Kasi Pemasaran Pariwisata dan TDUP Dinas Pariwisata dan Kebudayaan Kota Sungai Penuh) mengungkapkan:

"Untuk perencanaan pegembangan dari Bukit Khayangan ini, sekarang dalam proses. Setiap tahun kita usahakan ada perubahan pembangunan. Seperti misalnya, 2 tahun kebelakang tahun 2017 dan 2018 kita ada menambahkan gazebo, semacam tempat duduk itu, kurang lebih ada sekitar 8 kalo nggak salah. Rencananya tahun ini kita merenovasi icon bukit Khayangan, yaitu menara view kita bikin dua tingkat. Kemudian kita tambahkan fasilitas wc, ada 2 spot diatas dan dibawah selanjutnya penambahan area tempat orang berbelanja. Kedepannya kita merencanakan perluasan tempat parkir, karena tempat parkir disana bisa dikatakan masih sempit untuk kendaraan roda dua dan roda empat, sehingga diperlukan perluasan area agar terlihat lebih rapi, kemudian rencananya akan dibuat rumah pohon". (wawancara 18 November 2019)

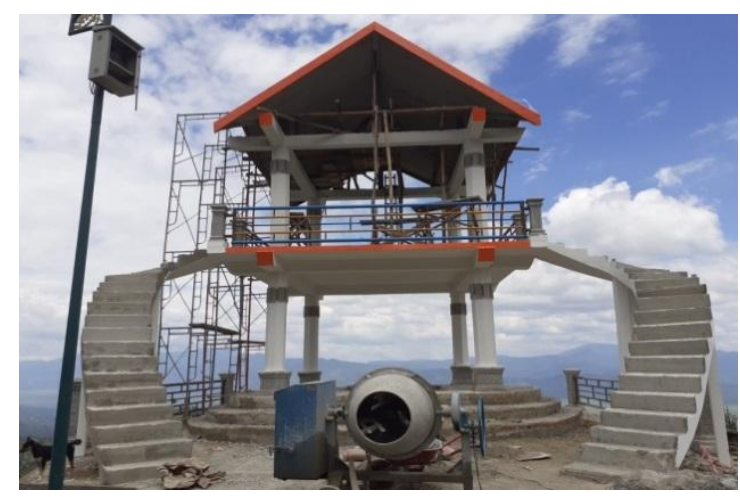

Gambar 1.1.Menara View Objek Wisata Bukit Khayangan

Dari temuan diatas,dapat dilihat bahwa pengembangan yang dilakukan oleh Dinas Kebudayaan dan Pariwisata Kota Sungai Penuh ini lebih fokus pada pengembangan objek. Seperti halnya yang penulis temukan dilapangan, pada objek wisata Bukit Khayangan juga terdapat semacam arena bermain anak, dengan begitu konsepnya lebih mengarah kepada wisata keluarga.

\section{Prasarana Wisata}

Untuk melihat sejauh mana pengembangan dalam prasarana wisata yang dapat berupasumber daya alam dan sumber daya buatan manusia baik itu berupa jalan, listrik, air, telekomunikasi, terminal, jembatan dan sebagainya.Ini dapat dilihat dari ungkapan pendapat Bapak Yan Kamal Syam (Kasi Bidang Pemasaran Pariwisata) mengungkapkan bahwa:

"Kendalanya hanya saja sekarang jalan menuju kesana lumayan kecil jadi agak sulit dilalui terlebih bagi yang berkendaraan roda dua harus lebih berhati-hati hal tersebut dikarenakan di satu sisi disana itu lokasi perladangan, sedangkan sebelahnya kan jurang. Karna kan jalan itu tidak hanya untuk ke Bukit Khayangan tetapi untuk masyarakat 
perladangan yang ada di atasnya itu, yaitu masyarakat di Desa Renah Kayu embun. Jadi disitu jalan itu dipakai oleh masyarakat dan juga dipakai oleh objek"(wawancara 18 November 2019)

Berdasarkan yang penulis temukan dilapangan, serta diperkuat dengan beberapa pernyataan dari hasil wawancara, faktor pendukung pengembangan sarana dan prasarana nya berupa aliran listrik dan saluran air, yang sudah tersedia dan sangat mendukung untuk kebutuhan bagi wisatawan yang berkunjung. Sedangkan yang menjadi faktor penghambat yang penulis temukan dilapangan, yaitu jalan menuju objek wisata yang bisa dibilang belum mencapai standar keamanan karena lumayan berbahaya untuk dilintasi dua kendaraan.

\section{Sarana Wisata}

Dalam rangka pengembangan objek wisata, tentu diperlukan kelengkapan berupa sarana wisata dengan tujuan memenuhi kebutuhan wisatawan yang berkunjung. Ini dapat dilihat dari ungkapan kutipan Bapak Zulwachdi S.Pd, M.Si (Kepala Dinas Kebudayaan dan Pariwisata Kota Sungai Penuh) mengungkapkan bahwa:

"Mengenai sarana wisata, mungkin yang menjadi faktor penghambatnya disini lebih kepada ketersediaan penginapan. Rencananya di Bukit Khayangan itu nantinya akan kita bangun semacam homestay. Selain itu, untuk transportasi umum juga belum ada, masyarakat masih menggunakan kendaraan pribadi atau kendaraan khusus yang untuk kesana, yang dipakai oleh orang-perorangan, atau per-kelompok."(wawancara 18November 2019)

Jadi dapat disimpulkan bahwa yang menjadi faktor penghambatnya adalah belum tersedianya penginapan. Berdasarkan yang penulis temukan dilapangan juga bahwasanya disana memang belum tersedia penginapan, hanya terdapat semacam Mess yang tidak terawat, dan disana tidak ada fasilitas selayaknya tempat yang bisa digunakan untuk dijadikan tempat beristirahat oleh para pengunjung. untuk hotel atau penginapan hanya terdapat di pusat kota.

\section{Tata Laksana}

Untuk melihat sejauh mana pengembangan yang dilakukan terhadap tata laksana atau infrastruktur pada objek wisata Bukit Khayangan yang juga merupakan faktor pendukung, baik itu berupa perbaikan jalan ataupun berupa bangunan fisik, dapat dilihat dari ungkapan pendapat Bapak Lerman (Kepala Desa Sungai Jernih) mengungkapkan bahwa:

"Memang ada beberapa titik yang rentan terjadi longsor dan kecelakaan, terlebih untuk jalur yang baru diaspal yaitu dari Desa Ulu Air menuju lokasi Bukit Khayangan 
ini, ya harapan kita, pemerintah Kota untuk segera melakukan perbaikan jalan untuk meningkatkan keselamatan warga" (wawancara 20 November 2019)

Berdasarkan kutipan wawancara tersebut, dapat dilihat bahwa masih terdapat faktor penghambat yang menjadi kendala dalam pengembangan objek wisata Bukit Khayangan ini yaitu pada infrastrukturnya, berupa pelebaran jalan serta perbaikan jalan dibeberapa titik yang dirasa rawan terjadi longsor, sehingga untuk kedepannya akan lebih meningkatkan keamanan dan kenyamanan bagi pengunjung.

\section{Masyarakat (Lingkungan)}

Untuk melihat sejauh mana keterlibatan masyarakat di kawasan objek wisata dalam mengetahui bermacam jenis serta bentuk pelayanan yang diperlukan oleh wisatawan, dapat dilihat dari ungkapan bersama Ibu Eka Puspita Dewi, S.Pd (Staf Pengelolaan Daya Tarik Wisata) mengatakan:

"Masyarakat sangat dilibatkan dalam pengembangan objek wisata Bukit Khayangan ini, disana juga terdapat semacam team yang dibentuk sebagai distributor tiket masuk yang dipercaya dari pihak Dinas sendiri, agar mengurangi tingkat kemacetan di area objek wisata Bukit Khayangan"(wawancara 15 November 2019)

Berdasarkan yang penulis temukan dilapangan, faktor pendukung nya yaitu masyarakat dilibatkan langsung dalam pengembangan objek wisata Bukit Khayangan ini, selain itu dengan adanya kegiatan-kegiatan yang diadakan untuk menarik minat pengunjung. Sedangkan faktor penghambatnya mungkin lebih kepada SDM, yang masih kurang kesadarannya akan kebersihan lingkungan, dan seperti yang penulis temukan dilapangan, banyak ditemukan coretan-coretan di gazebo atau tempat peristirahatan disana, kemudian atap-atap dari gazebo beberapa ada yang rusak, dan belum diperbaiki.

\section{Dampak Terhadap Ekonomi Pariwisata}

\section{Meningkatkan Kesempatan Kerja}

Pengembangan Objek wisata Bukit Khayangan sedikit banyaknya akan berdampak pada peningkatan ekonomi masyarakat di kawasan objek wisata tersebut, yang mana salah satunya berupa terbukanya lapangan pekerjaan yang direkrut langsung dari masyarakat sekitar oleh pengelola objek wisata Bukit Khayangan itu sendiri.Masyarakat juga ikut berpartisipasi dalam kegiatan pariwisata. Dengan begitu masyarakat akan mendukung penuh dalam pengembangan objek wisata Bukit Khayangan tersebut, karena dapat membawa dampak ekonomi yang positif.

\section{Menciptakan Kesempatan Berusaha}

Dengan meningkatnya jumlah pengunjung di objek wisata Bukit Khayangan, akan memberikan semacam peluang usaha yang bisa dimanfaatkan oleh 
masyarakat. beberapa peluang usaha tersebut diantaranya adalah dengan berdagang makanan atau minuman disekitar objek wisata. Ini bisa dilihat dari ungkapan kutipan darilbu Eka Puspita Dewi, S.Pd (Staf Pengelolaan Daya Tarik Wisata) mengatakan:

"Untuk jumlah pedagang disana itu bersifat kumulatif, karena melihat dia ada musimnya, kalau musim liburan banyak, kalau hari biasa paling 3 atau 4 yang jualan. Kalau hari libur mungkin bertambah, karena istilahnya mereka itu pedagang mobilitas gitu kan, dimana tempat yang ramai mereka datang. Kebanyakan dari desa situ, desa seputaran bukit khayangan, baik dari kumun, maupun daerah sungai jernih itu sendiri." (wawancara 15 November 2019)

Berdasarkan wawancara yang penulis lakukan, dapat dilihat bahwa masyarakat tidak terlalu tertarik berjualan ketika hari biasa, hal ini mungkin dikarenakan faktor lokasi objek wisata yang lumayan jauh, sehingga para pengunjung pun ramai hanya saat saat liburan saja.

\section{Meningkatkan pendapatan}

Dengan adanya masyarakat yang membuka usaha di sekitar objek wisata Bukit Khayangan, maka masyarakat akan memperoleh pendapatan tambahan yang ditunjang dengan semakin banyaknya jumlah wisatawan. Masyarakat dapat mengambil manfaat dari sektor pariwisata, yaitu dengan membuka usaha untuk meningkatkan pendapatan, meskipun pendapatan yang didapatkan tidak selalu menjanjikan, karena sifat musiman dari pariwisata yang tidak setiap harinya akan ramai oleh pengunjung.

\section{Kesimpulan}

Berdasarkan hasil pembahasan, maka dapat diambil suatu kesimpulan untuk menjawab rumusan masalah yang telah diajukan dalam penelitian ini yaitu tentang dampak pengembangan pariwisata dalam rangka meningkatkan kesejahteraan masyarakat dikawasan objek wisata Bukit Khayangan Kota Sungai Penuh. Dalam hal ini pengembangan pariwisata di Bukit Khayangan masih terus dilakukan dengan upaya peningkatan sarana prasarana serta daya tarik yang dimiliki oleh objek wisata Bukit Khayangan yang dulunya hanya berupalahan pertanian, namun setelah masuknya industri pariwisata maka juga akan menjadi perhatian bagi pemerintah untuk meningkatkan pembangunan di daerah sana.

Dari hasil penelitian ini menunjukkan bahwa objek wisata Bukit Khayangan telah memberi peran positif dalam meningkatkan kesejahteraan masyarakat. Secara umum, masyarakat merasakan pendapatan mereka bisa terbantu walaupun tidak dapat dipastikan bahwa objek wisata tersebut akan selalu ramai setiap harinya, serta masyarakat dapat merasakan bahwa dengan adanya pengembangan di sektor pariwisata juga dapat meningkatkan perekonomian dan membuka lapangan 
pekerjaan meskipun ada beberapa yang mengeluh mengenai pendapatan mereka yang tidak seberapa dihari biasa.

\section{Daftar Pustaka}

Suwantoro, Gamal. 2004. Dasar-dasar Pariwisata. Yogyakarta: Andi.

Hadinoto, Kusudianto. 1996. Perencanaan Pengembangan Destinasi Pariwisata. Jakarta: UI Press.

Sugiyono. 2012. Metode Penelitian Kuantitatif, Kualitatif dan RED. Bandung.

Aldri Frinaldi, Mesa Widya, dan Adil Mubarak 2019. Efektivitas Strategi Dinas Kebudayaan dan Pariwisata Kota Pariaman terhadap Kepuasan Pengunjung Di Pantai Gandoriah. Jurnal Spirit Publik Vol.14 No.1

Aldri Frinaldi, Fadhlan Rizky, dan Nora Eka Putri 2019. Penerapan EGovernment Dalam Promosi Pariwisata Melalui Website Oleh Dinas Kebudayaan dan Pariwisata Kota Padang.

Rahmita. 2017. Dampak Pengembangan Objek Wisata Ndayung Rafting Terhadap Sosial Budaya Dan Ekonomi Masyarakat. Jurnal Administrasi Bisnis. Vol.45 No.1, Hal: 179-187

Rosni. 2017. Analisis Tingkat Kesejahteraan Masyarakat Nelayan Di Desa Dahari Selebar Kecamatan Talawi Kabupaten Batubara. Jurnal Geografi. Vol.9 No.1. Hal 53-66

Undang-Undang No 10 Tahun 2009 tentang Kepariwisataan

Instruksi Presiden Republik indonesia Nomor 16 Tahun 2005 tentang Kebijakan Pembangunan Kebudayaan dan Pariwisata 